
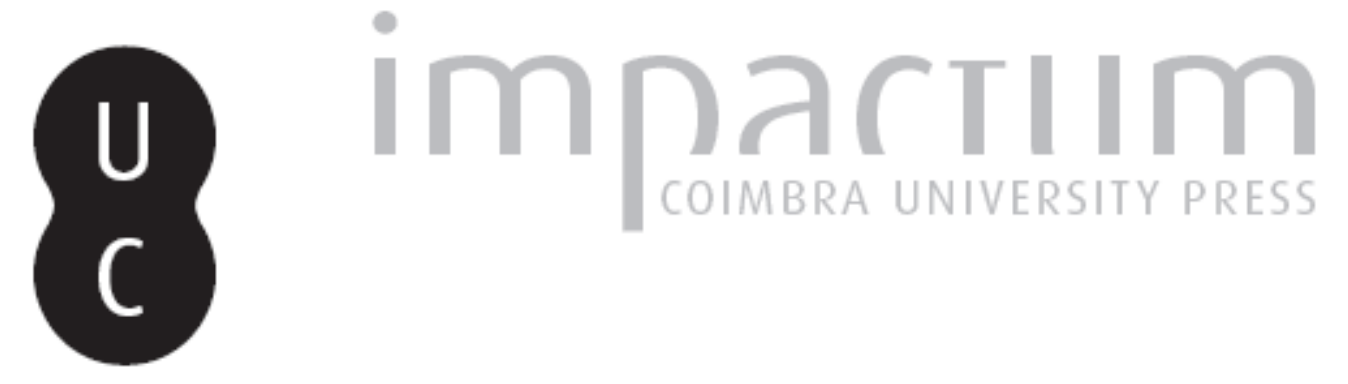

\title{
Questões epistemológicas em Wittgenstein
}

Autor(es): $\quad$ Venturinha, Nuno

$\begin{array}{ll}\text { Publicado por: } & \text { Faculdade de Letras da Universidade de Coimbra, Instituto de Estudos } \\ \text { Filosóficos }\end{array}$

URL persistente:

URI:http://hdl.handle.net/10316.2/35603

DOI:

DOI:http://dx.doi.org/10.14195/0872-0851_45_7

Accessed : $\quad$ 26-Apr-2023 14:55:24

A navegação consulta e descarregamento dos títulos inseridos nas Bibliotecas Digitais UC Digitalis, UC Pombalina e UC Impactum, pressupõem a aceitação plena e sem reservas dos Termos e Condições de Uso destas Bibliotecas Digitais, disponíveis em https://digitalis.uc.pt/pt-pt/termos.

Conforme exposto nos referidos Termos e Condições de Uso, o descarregamento de títulos de acesso restrito requer uma licença válida de autorização devendo o utilizador aceder ao(s) documento(s) a partir de um endereço de IP da instituição detentora da supramencionada licença.

Ao utilizador é apenas permitido o descarregamento para uso pessoal, pelo que o emprego do(s) título(s) descarregado(s) para outro fim, designadamente comercial, carece de autorização do respetivo autor ou editor da obra.

Na medida em que todas as obras da UC Digitalis se encontram protegidas pelo Código do Direito de Autor e Direitos Conexos e demais legislação aplicável, toda a cópia, parcial ou total, deste documento, nos casos em que é legalmente admitida, deverá conter ou fazer-se acompanhar por este aviso.

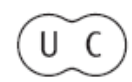




\section{REVISTA FILOSÓFICA DE COIMBRA}

vol. 23 - número 45 - março 2014

vol. 23 - número 45 - março 2014 Fundação Eng. António de Almeida

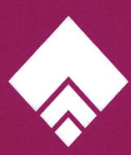




\title{
QUESTÕES EPISTEMOLÓGICAS EM WITTGENSTEIN
}

\author{
NUNO VENTURINHA*
}

(Coordenação e Introdução)

Este dossier foi preparado no âmbito do projecto $A s$ Investigações Filosóficas de Wittgenstein: Reavaliando um Projecto (PTDC/FIL-FIL/099862/2008), financiado pela Fundação para a Ciência e a Tecnologia, que coordenei no Instituto de Filosofia da Linguagem da Faculdade de Ciências Sociais e Humanas da Universidade Nova de Lisboa entre 2010 e 2013. Os artigos que o constituem foram apresentados em diferentes eventos promovidos pelo projecto na sua fase final. O primeiro, da autoria de Sofia Miguens, resulta de uma cooperação com o projecto Os Limites do Juízo: Frege, Agentes Cognitivos e Pensadores Humanos, igualmente financiado pela FCT, por si coordenado no Instituto de Filosofia da Faculdade de Letras da Universidade do Porto, tendo sido apresentado no IFL em Setembro de 2012. O segundo artigo, de Maria Luísa Couto Soares, membro do projecto As Investigações Filosóficas de Wittgenstein: Reavaliando um Projecto, decorre de uma apresentação feita no 1. ${ }^{\circ}$ Colóquio Luso-Brasileiro de Estudos Wittgensteinianos, que teve lugar no IFL em Julho de 2012, numa organização de António Marques, também membro do projecto. O terceiro, de António de Carvalho Pais, foi apresentado no IFL em Fevereiro de 2013, resultando do trabalho por si realizado num seminário de investigação doutoral em Filosofia Contemporânea oferecido pelo projecto na FCSH no $1 .^{\circ}$ semestre de 2012-2013, do qual fui responsável.

Os artigos que aqui se publicam abordam temas diversos mas têm em comum o facto de considerarem a filosofia da linguagem de Wittgenstein à luz de uma epistemologia muito peculiar que começa a adquirir os seus contornos numa observação das chamadas "Notes on Logic" de 1913, onde é

* Instituto de Filosofia da Linguagem da Faculdade de Ciências Sociais e Humanas da Universidade Nova de Lisboa. 
dito que "[a] epistemologia é a filosofia da psicologia", algo que seria incluído no Tractatus ${ }^{1}$. Com efeito, encontramos desde o pensamento inaugural de Wittgenstein a convicção de que qualquer "teoria do conhecimento" só se poderá constituir enquanto reconhecimento da operacionalidade mental que se promove de modo pré-reflexivo em nós, a qual se traduz num domínio linguístico que vai muito para além daquilo que as ciências da linguagem destacam. O que está em causa são características ontológicas do humano que estão condensadas na forma como usamos a linguagem, qualquer coisa que, segundo Wittgenstein, nem sempre mereceu um olhar atento ao longo da tradição filosófica, originando mal-entendidos que só podem ser sanados se atendermos à expressão mesma do nosso pensamento. Não é por acaso que a observação que se segue nas "Notes on Logic" indica que "[a] desconfiança relativamente à gramática é o primeiro requisito para o filosofar" Wittgenstein não quererá aqui dizer (similarmente a Nietzsche) que devemos desconfiar da gramática do nosso modo de ser tal como ela está fixada mas sim que precisamos de ter sempre em vista se aquela é observada, naquilo que dizemos e naquilo que os outros dizem.

Esta ideia poderá parecer trivial porque isso aparenta ser já aquilo que fazemos. As incoerências que tantas vezes identificamos ao nível proposicional sugerem que estamos alertas para tais factos, pressupondo a nossa mundividência uma linguagem com sentido. Wittgenstein não põe em questão essa pressuposição. Muito pelo contrário, o que ele entende é que ela necessita de ser constantemente tida em conta mas que muitas vezes, sobretudo no discurso filosófico, não o é. A apresentação tractariana da filosofia como "crítica da linguagem"3 inscreve-se nesta decisão em relação ao que efectivamente faz sentido dizer - e consequentemente pensar. Embora seja Russell que, para além de Mauthner, é mencionado a esse propósito, serão mais os "grandes trabalhos de Frege", de que Wittgenstein fala no Prefácio 4 , que guiarão esse desígnio. O denominado princípio do contexto, no qual Frege declara a necessidade de atendermos a proposições completas pois só aí poderão os seus constituintes alcançar uma significação, está na base do empreendimento tractariano, tal como a diferenciação que Frege reclama entre aquilo que é de índole psicológica ou subjectiva e o que é de ordem lógica ou objectiva, pensada em contiguidade com a distinção entre conceptualidade e objectualidade ${ }^{5}$. Ao pretender ir ainda mais longe do que Frege no que

1 Wittgenstein 1979, 106. Cp. Wittgenstein 1933, 4.1121b, onde "epistemologia" é trazida à expressão por "Erkenntnistheorie".

2 Wittgenstein 1979, 106.

3 Cf. Wittgenstein 1933, 4.0031.

${ }^{4}$ Cf. ibid., 28.

5 Cf. Frege 1988, x, bem como $\S \S 60$ e 62. 
concerne à teoria da significação, Wittgenstein refere num apontamento de 2 de Setembro de 1914, um dos primeiros que anota nos seus cadernos de guerra subsistentes e que passaria para o Tractatus', que para Frege o "sentido" (Sinn) de qualquer acto proposicional diria fundamentalmente respeito à sua formação legítima, ou seja, à sua correcção gramatical, algo que, no entender do autor do Tractatus, tem que ver somente com a própria possibilidade proposicional. Aquilo que se passa, segundo ele, é que o "significado" (Bedeutung) pode ter sido ilusoriamente atribuído às palavras, formando assim pseudoproposições - que são agramaticais por serem insignificativas. No entanto, que Frege estivesse cego para esta questão é algo que parece ser desmentido por uma passagem do seu célebre artigo "Sobre Sentido e Significado", sendo dito que "[t]alvez possamos admitir que uma expressão gramatical correctamente formada que está para um nome próprio tem sempre um sentido", acrescentando ele que "isto não é dizer que ao sentido também corresponde um significado"7.

O que temos aqui não são simples problemas linguísticos mas a própria substancialidade de muitas das nossas enunciações. A espontaneidade com que usamos a linguagem faz-nos esquecer do verdadeiro conteúdo disso que dizemos e pensamos, estando por isso em jogo não a performance ao nível estritamente linguístico mas todo um horizonte de inconsequência significativa que não é reconhecido nem no senso comum nem em grande parte da filosofia. A crítica principal que Wittgenstein tem em vista é, justamente, à extensão operada pela especulação filosófica face ao ponto de vista comum, não se traduzindo o filosofar num autêntico desvelamento das determinações que naturalmente nos estruturam mas laborando, a contrario sensu, positivamente nessa mesma base.

A interpretação de Wittgenstein feita pelos chamados "novos wittgensteinianos" desde os anos 80 do século passado, nomeadamente por Cora Diamond e James Conant, abriu linhas de leitura incontornáveis a este respeito, impondo que o "sem-sentido" (Unsinn) de que fala o Tractatus, especialmente no seu final, deve ser interpretado em toda a sua austeridade ou plenitude e não como algo que se reconheça ser assim, sem sentido, ainda que se julgue poder compreender o seu teor, seja aceitando-o, a exemplo daquilo que uma hermenêutica de cariz metafísico sugeriu, seja recusando-o, na medida em que o fez a escola positivista. O "sem-sentido" é obviamente isso mesmo, mas, tal como Wittgenstein procurou ir para além do próprio Frege, também os leitores "austeros" ou "resolutos" parecem querer radicalizar o Tractatus,

${ }^{6}$ Cf. Wittgenstein 1979, 2, e Wittgenstein 1933, 5.4733. Os cadernos abrem, justamente, com a ideia (fregiana) de que "[a] lógica deve cuidar de si própria" (Wittgenstein 1979, 2; Wittgenstein 1933, 5.473).

7 Frege 1967, 28 (na paginação original do artigo). 
passando ao lado ou por cima de documentos onde o seu propósito se patenteia. É que, para Wittgenstein, o "sem-sentido" é o que é, no mais das vezes, na tensão problemática em que inalienavelmente se constitui, não sendo, por isso, algo do qual possamos verdadeiramente prescindir. Isto não é idêntico a afirmar que se consegue ver o que aí está presente, que, portanto, se entende isso; longe disso, trata-se, tão-somente, de diagnosticar com total realismo o carácter incontornável dessa projecção nas nossas vidas, em toda a vacuidade de que se reveste. É essa superação que o Tractatus requer de nós, qualquer coisa que as Investigações Filosóficas pretendem exponenciar ${ }^{8}$. De facto, a ironia propositada que os "novos wittgensteinianos" adjudicam ao Tractatus - uma obra cujas próprias proposições são reconhecidas pelo seu autor como unsinnig $^{9}$ - é problemática não só face a documentação da época mas também no tocante à segunda fase do pensamento wittgensteiniano. Essa é a razão pela qual tal leitura, sobretudo através de Conant, tem recentemente procurado apresentar um quadro interpretativo que possa adequar-se ao conjunto do que Wittgenstein escreveu, atenuando o próprio estatuto irónico da discursividade $\operatorname{tractariana}^{10}$. O "último Wittgenstein" é, nesta visão mais actual, o filósofo que a partir de 1937, altura em que prepara a versão inicial das Investigações, defende uma abertura traduzida num "pluralismo metodológico", consagrado no $\$ 133$ do livro publicado postumamente, corrigindo o "monismo metodológico", quer do "primeiro Wittgenstein", quer do "Wittgenstein intermédio", ainda que este último já pretendesse, com a noção de "gramática", afastar-se do dogmatismo tractariano ${ }^{11}$. O desenvolvimento da filosofia wittgensteiniana aparece ligado, principalmente, ao desenvolvimento do seu próprio ideal de clarificação ou elucidação lógico-gramatical da linguagem.

Ora, mais do que a justeza interpretativa da proposta "austera" ou "resoluta", é o alcance clarificativo ou elucidativo frisado por essa abordagem que Sofia Miguens destaca na sua análise de um "alien lógico", retomando uma discussão que Frege trava com Erdmann no Prefácio às Leis Fundamentais da Aritmética e que Conant recupera num importante artigo do início dos anos 90. Aquilo que Miguens sublinha é a importância de se considerar seriamente o antipsicologismo que Frege sustenta relativamente às verdades da lógica, o qual, segundo Conant, conduzirá à Sinnlosigkeit destas no Tractatus. A maneira como, na sequência do trabalho de Conant, Miguens contrapõe as propostas psicologistas de Descartes ou Quine às antipsicologistas de Kant ou Frege reveste-se do maior interesse não só para o entendimento da

8 Para uma discussão do escopo do Tractatus e da leitura "resoluta", ver Venturinha 2010, $\S 13$ e 14.

9 É isto que nos diz a penúltima proposição, a 6.54 .

10 A este respeito, ver Conant 2011.

11 Cf. ibid., 633 ss. 
metodologia tractariana mas também para a compreensão do projecto das Investigações. É muito relevante que em 1937, numa série de observações que seriam seleccionadas para a segunda parte da versão inicial dessa obra - segunda parte essa que, num arranjo subsequente do texto, foi publicada postumamente na Parte I das Observações sobre os Fundamentos da Matemática -, Wittgenstein tenha comentado criticamente o antipsicologismo de Frege, defendendo uma posição bem diferente da assumida no Tractatus ${ }^{12}$. As "leis da lógica" são agora vistas, nos seus múltiplos alcances epistemológicos, enquanto "hábitos do pensamento", traduzindo-se numa imagem englobante da experiência humana do "pensar", alicerçada num sistema de regras que excede incomensuravelmente o domínio da lógica formal, onde uma Begriffsschrift - estabelecida no Tractatus por meio de um processo imanente e não axiomático - podia meramente tornar mais conspícua a Unsinnigkeit de muitas das nossas formulações. É deveras interessante que Wittgenstein aluda nesta altura ao passo fregiano que catapultou a análise de Conant embora pareça extrair daí o oposto daquilo que este veria o autor do Tractatus concluir, senão leia-se:

Frege diz no Prefácio das "Leis Fundamentais da Aritmética”: “... temos aqui uma espécie de loucura até agora desconhecida" - mas ele nunca indicou como seria realmente esta "loucura"13.

A mutabilidade das "leis do pensamento" que, segundo Frege, adviria do facto de "leis naturais do tomar por verdadeiro humano" - psicológicas - passarem a ter o mesmo estatuto de "leis do ser verdadeiro" - lógicas ${ }^{14}$ - é, para o autor das Investigações, ilusória, tão ilusória quanto Conant a vê em Frege e naquilo que o Wittgenstein do Tractatus teria visto em Frege. É, pois, notável que em 1937 Wittgenstein veja Frege a admitir um alien lógico - alguém que não pensasse de acordo com o nosso Fürwahrhalten - e a criticá-lo por isso ${ }^{15}$.

12 Ver, especialmente, Wittgenstein 1974, I, §§131-2. Uma exposição detalhada desse criticismo, o qual envolve outras observações do espólio, pode ser encontrada no meu artigo "The Epistemic Value of Holding for True", a publicar no Journal of Philosophical Research.

13 Wittgenstein 1974, I, §152. Esta observação decorre do MS 117, 49, um volume iniciado a 11 de Setembro de 1937, encontrando-se um esboço num apontamento datado de 29 de Agosto desse ano, onde Wittgenstein deixa um espaço em branco para incluir a citação e onde se refere a "Wahnsinn" em vez de "Verrücktheit", que é o termo que Frege usa para "loucura" (cf. Wittgenstein 2000, MS 118, 36v).

14 Cf. Frege 1966, xvi.

15 Conant (1991, 176, n. 98), não deixa de notar que Wittgenstein iria retomar esta problemática fregiana, remetendo o leitor para o espaço textual dos $\S \S 131-54$ das Observações, assim como para passos análogos nas aulas sobre os fundamentos da 
A observação parentética que no manuscrito, bem como nos dactiloscritos, se segue à que foi citada, embora tenha vindo a ser impressa nas Observações antes daquela, mostra-nos bem Wittgenstein a tentar imaginar, procurando seguir Frege, essa possibilidade de "loucura":

Uma sociedade que agisse assim lembrar-nos-ia talvez das "pessoas espertas" nos contos de fadas ${ }^{16}$.

Que seja feito esse exercício por parte de Wittgenstein é algo totalmente compreensível se tivermos em atenção a abertura que o seu pensamento passa a ter para concretizações lógicas que antes tinham sido preteridas e sem cuja admissão a lógica do humano se dilacera. Compreender o criticismo wittgensteiniano significa compreender a lógica em toda a sua fixidez mas também multiplicidade, sendo por isso preferível o termo gramática para dar conta do que regula os diversos jogos de linguagem em que nos movemos e que trazem consigo toda uma "história natural do homem"17.

$\mathrm{O}$ distanciamento das Investigações face à concepção fregiana (e tractariana) da lógica é, justamente, o tópico do artigo de Maria Luísa Couto Soares. Ao analisar vários textos dos anos 30 , esta mostra como a vagueza conceptual que Frege pretendera erradicar da linguagem lógica é assumida no "segundo" Wittgenstein de forma determinante na medida em que só nos usos quotidianos da linguagem poderemos identificar a lógica enquanto tal. Tal vagueza vai caracterizar o próprio tipo de questionamento filosófico que já não visará um enquadramento definitivo, nem que seja minimal ou negativo como sucedeu com a forma geral da proposição ("tal e tal é o caso"; se quisermos ser mais literais, "passa-se assim e assim"18) ou com a ética ("É claro que a ética não se deixa pôr em palavras"19), vista, exactamente, como "transcendental" 20 . A pergunta "o que é X?" é ela própria sujeita a uma análise gramatical no tocante àquilo que se visa aí, sendo decisivo superar o ideal

matemática de 1939 (Wittgenstein 1976, 201-3). No entanto, ele vai simplesmente dizer: "Parte daquilo que lhe interessa, no seu recorrer a estas páginas, é a questão: que tipo de actividade de criticismo filosófico está envolvida numa tal experiência mental? Como é que ela fornece iluminação?” A restante parte dirá respeito a isto mesmo que procurei expor. Ver adicionalmente Conant 1991, 177, n. 109.

16 Wittgenstein 2000, MS 117, 49; cp. TS 221, 174; TS 222, 118; Wittgenstein 1974, I, $\S 151$.

17 É relevante que esta noção ocorra numa observação que aparece tanto entre as que foram mencionadas das Observações (cf. Wittgenstein 1974, I, §142) como nas Investigações (cf. Wittgenstein 2009, I, §415).

18 Cf. Wittgenstein 1933, 4.5(3)b.

19 Ibid., 6.421(1).

20 Cf. ibid., 6.421(2). 
ou os ídolos de que Wittgenstein repetidamente fala nas Investigações por forma a identificarmos com nitidez os sem-sentidos que bloqueiam o nosso entendimento (natural e filosófico). Isso é algo que só um enfoque dos conceitos psicológicos dos quais nos servimos no dia-a-dia pode realizar pois é neles que se acha expressa a essência disso que somos e que nos habilita, portanto, a pôr certas questões mas não outras, as quais devem ser consideradas como sem sentido.

Partindo de observações sobre causa e efeito registadas num outro documento do ano de 1937, o MS 119 do Nachlass, António de Carvalho Pais estende a análise aos conceitos epistémico-psicológicos que fundamentam as nossas experiências de expectativa, desejo ou justificação, pensadas em termos de "necessidade lógica", algo que será insistentemente trabalhado por Wittgenstein nos últimos anos da sua vida. O que este artigo explora é a extraordinária complexidade na qual assenta o processo de crença do humano, enraizado nessa "história natural" que é também aqui destacada, fazendo ver por que é que a epistemologia qua filosofia da psicologia, bem mais do que a filosofia da matemática, constitui o terreno reflexivo par excellence do projecto das Investigações.

\section{Referências}

Conant, J. 1991. "The Search for Logically Alien Thought: Descartes, Kant, Frege, and the Tractatus", Philosophical Topics 20, 1: 115-80.

-----. 2011. "Wittgenstein's Methods", in The Oxford Handbook of Wittgenstein, eds. O. Kuusela e M. McGinn. Oxford: Oxford University Press.

Frege, G. 1966. Grundgesetze der Arithmetik: Begriffsschriftlich abgeleitet, vol. I. Hildesheim: Georg Olms.

-----. 1967. "Über Sinn und Bedeutung", in Kleine Schriften, ed. I. Angelelli. Hildesheim: Georg Olms.

------. 1988. Die Grundlagen der Arithmetik: Eine logisch-mathematische Untersuchung über den Begriff der Zahl, ed. C. Thiel. Hamburg: Felix Meiner.

Venturinha, N. 2010. Lógica, Ética, Gramática: Wittgenstein e o Método da Filosofia. Lisboa: Imprensa Nacional-Casa da Moeda.

Wittgenstein, L. 1933. Tractatus Logico-Philosophicus, rev ed. London: Routledge \& Kegan Paul.

-----. 1974. Bemerkungen über die Grundlagen der Mathematik, eds. G. E. M. Anscombe, R. Rhees e G. H. von Wright. Frankfurt am Main: Suhrkamp.

-----. 1976. Wittgenstein's Lectures on the Foundations of Mathematics: Cambridge 1939, ed. C. Diamond. Ithaca, NY: Cornell University Press. 
1979. Notebooks 1914-1916, eds. G. H. von Wright e G. E. M. Anscombe. Oxford: Blackwell.

-----. 2000. Wittgenstein's Nachlass: The Bergen Electronic Edition. Oxford: Oxford University Press.

------ 2009. Philosophical Investigations, eds. P. M. S. Hacker e J. Schulte. Oxford: Wiley-Blackwell. 